\title{
Detecting Early Preclinical Alzheimer's Disease via Cognition, Neuropsychiatry, and Neuroimaging: Qualitative Review and Recommendations for Testing
}

\author{
Sylvie Belleville ${ }^{\mathrm{a}, \mathrm{b}, *}$, Céline Fouquet ${ }^{\mathrm{a}}$, Simon Duchesne ${ }^{\mathrm{c}, \mathrm{d}}$, D. Louis Collins ${ }^{\mathrm{e}, \mathrm{f}}$, Carol Hudon ${ }^{\mathrm{c}, \mathrm{g}}$ \\ and the CIMA-Q group ${ }^{\mathrm{h}}$ \\ ${ }^{a}$ Centre de recherche de l'Institut Universitaire de Gériatrie de Montréal, Montréal, QC, Canada \\ ${ }^{\mathrm{b}}$ Département de psychologie, Université de Montréal, Montréal, QC, Canada \\ ${ }^{\mathrm{c}}$ Centre de Recherche de l'Institut Universitaire en Santé Mentale de Québec, Québec, QC, Canada \\ ${ }^{\mathrm{d}}$ Département de radiologie, Université Laval, Québec, QC, Canada \\ ${ }^{\mathrm{e}}$ Biomedical Engineering Department, McGill University, Montreal, QC, Canada \\ ${ }^{\mathrm{f}}$ Montreal Neurological Institute, McGill University, Montreal, QC, Canada \\ ${ }^{\mathrm{g}}$ École de psychologie, Université Laval, Québec, QC, Canada \\ ${ }^{\mathrm{h}}$ Consortium for the Early Identification of Alzheimer's disease-Quebec
}

\begin{abstract}
In this paper, we review studies that have investigated whether neuropsychological, neuropsychiatric, and neuroimaging measures predict decline to Alzheimer's disease (AD). Prospective neuropsychological studies indicate that cognitive performance may be an excellent indicator of future progression from mild cognitive impairment (MCI) to AD, particularly when episodic memory is combined with tasks relying on executive control and language tasks. Research on neuropsychiatric symptoms reveal that depression, apathy, anxiety, and sleep disturbances can contribute to predictive models, though their sensitivity is typically lower than that found with cognitive measures. Finally, different structural brain imaging markers reveal excellent predictive accuracy. The paper discusses issues that will have to be addressed in future studies. First, it will be necessary to increase the evaluation of combined markers, as this may considerably improve predictive accuracy. Second, it will be necessary to move to earlier stages than MCI in order to expand the detection window. Third, processes of compensation and plasticity will have to be better investigated as research moves into earlier stages. The Consortium for the early identification of AD-Quebec (CIMA-Q) is presented as an instance of this approach, and potential batteries of measures are proposed.
\end{abstract}

Keywords: Alzheimer's disease, cognition, early detection of disease, longitudinal studies, mild cognitive impairment, neuroimaging, neuropsychiatry

\section{INTRODUCTION}

Alzheimer's disease (AD) is currently diagnosed when affected patients meet criteria for dementia, a

\footnotetext{
*Correspondence to: Sylvie Belleville, PhD. Centre de Recherche de l'Institut Universitaire de Gériatrie de Montréal, 4565 Chemin Queen Mary, Montréal, QC, H3W 1W5, Canada. Tel.: +1 514340 3540/Ext. 4760; Fax: +1 514340 3530; E-mail: sylvie.belleville@umontreal.ca.
}

stage at which the brain has suffered sufficient damage to severely impact cognition and autonomy. There is increasing recognition that such a late diagnosis poses major challenges for managing the disease and finding effective therapies. Recognizing $\mathrm{AD}$ when persons experience only very mild cognitive deficits or subjective symptoms would support the development of disease-modifying therapies, the identification of a more appropriate therapeutic window, and the 
determination of individuals who would benefit most from early interventions.

Studies on mild cognitive impairment (MCI) can be particularly contributive. Persons with MCI present a cognitive complaint that is confirmed with neuropsychological testing, but do not meet the diagnostic criteria for AD. A large proportion of those individuals will develop dementia, marking the condition as a likely disease prodrome. There is also growing interest for a subjective cognitive impairment phase (SCI), preceding MCI [1]. In SCI, individuals present a cognitive complaint but perform in the normal range on classical neuropsychological tests. Importantly, not all SCI or even MCI develop dementia, an uncertainty that challenges clinicians [2]. Researchers can investigate the difference between stable and declining individuals as a way to investigate the earliest manifestations of AD. In this paper, we present a narrative review of longitudinal studies that have assessed the predictive accuracy of cognitive, neuropsychiatric, and structural brain imaging measures in MCI and SCI. The initial selection of papers was based on the PRISMA guidelines [3] and the PICOS method was used to determine the research question and keywords. Because of space constraint, only the most relevant papers will be presented here. Our purpose is to recommend a combination of tests or measures that provide the best overall predictive accuracy for clinical practice or future studies.

\section{COGNITION IN PRECLINICAL AD}

Neuropsychological examination provides information about the presence, nature, and severity of cognitive deficits. It plays a key role in identifying $\mathrm{AD}$ and its MCI phase; greater knowledge regarding the impairment of specific cognitive domains can have enormous implications for the prediction of functional outcomes and for intervention planning.

Episodic memory refers to the record of personal events registered within a spatio-temporal context. Studies of MCI have indicated the presence of impaired episodic memory, a deficit that can be evidenced using verbal or visuo-spatial material [4-6] or with free or cued recall [4, 6-8]. Studies that have investigated the conditions underlying this memory impairment indicate a reduced ability to meaningfully encode an item [7-9]. Associative memory is the ability to associate previously unrelated items presented together or to associate one item to its spatial or temporal context. Many studies have reported impaired associative memory in MCI $[4,6,9,10]$ and a reduced level of memory recollection $[11,12]$. Such deficits would reflect the early hippocampal dysfunction found in MCI. These findings indicate that memory conditions that predominantly engage recollective/associative abilities would be most sensitive to the early phases of AD. Working memory is also impaired in MCI, particularly in tasks involving on-line manipulation of information such as sentence span [13] or alphabetical recall. Furthermore, short-term retention is more impaired when delayed with interference-filled intervals in the BrownPeterson procedure [13-15] or when increasing item length in the sentence and operation span tasks [13]. Executive control-a process involved in tasks that are new or demanding-is severely impaired on tasks of inhibition (Hayling test [16, 17], Stroop [14, 18], rule breaking in the Tower of London [19], Flanker task [20]). Divided attention [21], and global switching [22] were also found to be impaired. There is thus substantial evidence for a broad impairment of executive functions and attentional control in MCI.

A large number of studies have examined the accuracy of cognitive tests to predict progression from MCI to $\mathrm{AD}$. In this section, we will present those that have reported excellent overall predictive accuracy $(>80 \%)$. Unsurprisingly, studies have revealed that a range of episodic memory tests are excellent predictors of future decline. For instance, different versions of word recall tests (Selective Reminding Test [23, 24]; Free and Cued Selective Reminding Test (FCSRT) [6, 25-27]; California Verbal Learning Test [28]; Rey Auditory Verbal Learning Test, RAVLT $[29,30])$ and Story recall $[28$, 31-33] tasks were found to have excellent predictive accuracy. Visual recall or recognition is less frequently reported as a strong predictor of progression [27, 33, 34]. Note that measures of non-memory domains (e.g., naming or category fluency $[26,35,36]$ ) were not found to be excellent predictors, unless used in combination with episodic memory measures (see below).

Multivariate analysis helps identify which combination of tests best predicts progression. One important finding from studies that relied on multivariate models was that a combination of memory and executive functions or language is particularly useful to predict future decline in MCI [30, 34, 37]. The mental control subtest of the Wechsler Memory Scale combined with RAVLT delayed recall was shown to have a classification accuracy of $89 \%$ in memory-impaired non-demented patients, two years before AD diagnosis [30]. Similarly, high predictive accuracy was found when combining episodic memory with naming [38, 39] or verbal fluency [27, 40, 41]. Particularly high prediction values were obtained when combin- 
ing memory with more than one other domain. For instance, Belleville et al. followed 122 participants over an average of 4.5 years and found that a battery of tasks evaluating episodic memory (story recall and word lists), semantic memory (object naming and object decision), perception (orientation match from the Birmingham Object Recognition Battery), and working memory (Alpha span) showed an overall predictive value of $87.7 \%$ (sensitivity: $88 \%$, specificity: $87.1 \%$ ) to predict conversion from MCI to AD [42]. In another study, three computerized tests (abstract figure construction, verbal fluency, and delayed narrative recall) provided an overall predictive accuracy of $96 \%$ for conversion from MCI to AD (specificity: 99\%, sensitivity: 73\%) over two years [43]. Didic et al. [33] reported that combining two verbal tests (delayed story recall and object drawing recognition) provides a perfect accuracy (100\%) in predicting MCI with amnestic presentation 3.5 years before the diagnosis, although this was done with a very small sample size $(n=26$ at baseline).

The few longitudinal studies that have been used to identify predictors of progression to $\mathrm{AD}$ in cognitively intact older adults with a subjective complaint (SCI) typically show lower predictive accuracy than those in MCI. Derby et al. [44] showed that the FCSRT was more predictive than the Logical Memory subtest (for the four-year follow-up, sensitivity: $80.9 \%$ and $66.7 \%$; specificity: $81.7 \%$ and $72.9 \%$ for FCSRT and Logical Memory, respectively). Jessen et al. [45] found that the best set of baseline predictors from SCI to dementia 4.5 years later comprised delayed word recall, semantic verbal fluency and MMSE performance (sensitivity: 79.6\%; specificity: 66.4\%). Similarly, Jungwirth et al. [46] found that verbal memory and visual motor speed performance predicted $\mathrm{AD}$ over five years in people who were non-demented at baseline (sensitivity: 82.8\%; specificity: $82.4 \%$ ). As was the case for MCI, results in SCI indicate stronger predictive accuracy when measures of episodic memory are associated with measurements of other cognitive domains, particularly the executive domain.

\section{NEUROPSYCHIATRIC SYMPTOMS AND SUBJECTIVE COMPLAINTS IN PRECLINICAL AD}

Several longitudinal studies have revealed that neuropsychiatric manifestations and subjective complaints can be observed throughout the preclinical trajectory several years before MCI or AD onset [1]. Results from the Baltimore Longitudinal Study of Aging [47] indicated that larger levels of complaints on the Cognitive Failures Questionnaire were related to accelerated objective memory decline over 11.5 years. Moreover, Jessen et al. [45] found that SCI accompanied by worry were associated with a higher risk of dementia over a 4.5-year follow-up compared to those who did not worry about their memory decline. Jessen et al. [48] also found that progression was as frequent in SCI accompanied by worry as in early MCI. These findings suggest that identifying the worrisome aspect of subjective memory impairment is critical to predict future cognitive decline in preclinical AD. Qualifying it as worrisome or not may thus be a critical way to differentiate older adults experiencing cognitive changes due to aging from those enduring more than the usual effects of aging [49, 50].

Neuropsychiatric manifestations can also help predict progression to dementia. In a clinical sample of 60 individuals with MCI, melancholic symptoms and the persistence of depression over two to three years significantly increased the risk of AD (sensitivity: 76\%; specificity: 66\%) [51]. In a study of 51 persons with MCI, both depression and apathy predicted progression to AD over two years [52]. Note however, that some studies failed to find an increased risk of developing $\mathrm{AD}$ in the presence of depression [53]. Interestingly, the same study revealed that persons with MCI experiencing apathetic symptoms were nearly seven times more likely to progress to AD than MCI without apathy (sensitivity: $35.3 \%$; specificity: $92.7 \%$ ) [53]. Finally, in a population-based sample, sleep problems in individuals with MCI almost tripled the risk of progressing to AD after two years [54].

\section{STRUCTURAL IMAGING IN PRECLINICAL AD}

The relationship between MRI measures and pathophysiological changes in AD has been well researched. The distribution of amyloid and tau pathology identifies stages in the disease propagation that follows a distinct sequence [55] and MRI can track this brain change pattern [56]. In addition, MRI is clinically valid. It is not invasive, it can be repeated with no risk for the patient and it is often used in clinical practice to exclude other causes for the cognitive changes. Because anatomical MRI is potentially quite sensitive to the early $\mathrm{AD}$ phase and is widely available in clinical practice, we restricted our review to this neuroimaging component. 
In the MCI population progressing to $\mathrm{AD}$, hippocampal (HC) and entorhinal cortex atrophy has some predictive value [57-59]. Fleisher et al. found that manually defined $\mathrm{HC}$ volume alone predicted conversion from MCI to AD (60\% accuracy), and when combined with clinical data, predictive accuracy increased to $78.8 \%$ [60]. Stewart et al. [61] found that SCI was associated with lower HC volumes and temporal white matter lesions. In a smaller but similar sample followed longitudinally [62], there was an association between $\mathrm{HC}$ volume change and subjective memory impairment at follow-up, and this relation was stronger in participants with the APOE $\varepsilon 4$ allele. Thus, HC volume seems to be an early indicator of growing cognitive impairment.

Medial temporal lobe atrophy has also been found to be a significant predictor of conversion from MCI to AD [63]. Risacher et al. reported a similar global atrophy pattern in MCI converters and $\mathrm{AD}$, and showed that baseline medial temporal atrophy was associated with conversion [64, 65] (see also [66]). Whole brain and ventricular volumes have also been shown to predict progression, although the overall predictive accuracy level was relatively low [67]. A difference in cortical thickness has been found between normal controls, MCI and AD groups, as well as between stable and converting MCI subjects [68]. Cortical thinning [25] was associated with a $75 \%$ accuracy to discriminate progressor from stable MCI over a 2-year follow-up of 45 persons with MCI (specificity: 86.4 ; sensitivity: 61.1 ) and predictive accuracy was improved when cortical thinning measures (right anterior cingulate) were associated with memory measures (word recall and recognition), reaching an overall accuracy of $87.5 \%$ (sensitivity: 83.3; specificity: 90.9).

Machine learning approaches using structural MRI can detect non-focal changes in the temporal lobe that have predictive value for the development of $\mathrm{AD}$. In a group of 31 subjects with amnestic MCI, 22 of whom progressed to AD over an average of 2.2 years, Duchesne et al. obtained $81 \%$ overall accuracy (sensitivity: 70\%; specificity: 100\%) with MRI measures [69]. Fan et al. have found high predictive accuracy in $30 \mathrm{MCI}$ subjects when combining MRI and PET, with AUC of 0.98 [70]. In SCI, Peter et al. have characterized the gray matter patterns of $24 \mathrm{SCI}$ and 53 controls [71] and found greater similarity to an AD gray matter pattern in SCI compared to controls, and episodic memory decline was associated with an AD gray matter pattern. Thus, structural MRI measures are sensitive to the earliest signs of cognitive impairment related to AD.

\section{CONCLUSION AND FUTURE DIRECTION}

An analysis of longitudinal studies of SCI and MCI identifies a range of potential markers for prodromal and preclinical AD. For cognition, excellent predictive levels $(>80 \%)$ can be found using episodic measures, but better accuracy is obtained by adding executive and/or language tests. In general, combining cognitive tests helps predict conversion from MCI to dementia well above an $80 \%$ level of accuracy. For neuroimaging, a range of structural measures were identified as good predictors of future decline and some studies have reported excellent predictive accuracy as well. Although studies combining cognitive and neuroimaging measures are not frequent, they systematically report that this combination substantially improves their predictive models. Neuropsychiatric symptoms were found to contribute to predictive models. It is notable, however, that neuropsychiatric symptoms have much lower predictive accuracy than cognitive measures or brain imaging. This is due in large part to the fact that they have relatively low sensitivity compared to their specificity. This pattern reflects the possibility that those symptoms are only found in a particular subgroup of patients. Practically, it means that their presence signals an elevated risk of future $\mathrm{AD}$, although their absence does not necessarily indicate that the patient is protected against the disease.

Most of the previous studies aforementioned have limitations. First, in many cases, their design was retrospective: a prospective design is necessary to distinguish reference standard from predictive tests. Secondly, most studies have relied on clinical tests, while more sophisticated tests are likely to be more sensitive and/or specific (e.g., [42]). Similar issues were found in neuroimaging studies. For instance, HC volumes are variable and there is considerable overlap with normal aging [72]. Some of the variance may result from the difficulty in accurately measuring $\mathrm{HC}$ volume. The use of standardized, quantitative, automated programs for calculating $\mathrm{HC}$ volumes will reduce this source of variance. Amongst the reviewed studies, most report predictive accuracies over a 2-3 year period, which is relatively short. This is in part due to methodological constraints, as many studies have a relatively short follow-up. Furthermore, the majority of these studies enrolled MCI patients, who progress to dementia at a rate of about $15 \%$ per year; most will have converted after a 3-4 year period. MCI is as a highly dynamic prodromal period, and not the optimal one in which to identify the earliest markers of $\mathrm{AD}$. As one moves away from the time of the diagnosis, 
the magnitude of the effects will likely be reduced and logically, studies that investigated methods to predict $\mathrm{AD}$ in $\mathrm{SCI}$ reported lower predictive accuracies than those on MCI.

It is likely that, as one moves earlier into the disease time course, concepts such as brain reserve, plasticity, and compensation will influence symptom expression and development. Increasing evidence indicates that during the early MCI phase, some individuals compensate structural brain changes by increasing functional recruitment (a pattern referred to as hyperactivation) [73-76]. This suggests that task-related activation as measured by PET or fMRI might represent a powerful biomarker for early $\mathrm{AD}$, and could be used to understand why structural changes are not perfect predictors of future decline. However, these mechanisms may vary among individuals as a function of their accumulated or genetically determined brain reserve. Furthermore, neuroimaging brain changes evidenced decades before the earliest signs of cognitive impairment may not be so much signs of neurodegeneration but the expression of genetic risk states for $\mathrm{AD}$, and/or markers of inter-individual variability of cognitive per- formance due to genetic or environmental factors [77]. So far, most studies have assumed that measures contribute in a systematic and coordinated manner to disease expression. However, as the field moves into earlier phases, it will be necessary to have a more complex approach and to assess the combination of predictors, their interactions, and the role of protective and compensatory factors on disease expression.

The goal of this review was to identify predictors supporting the early identification of AD. Our research indicates that clear markers of $\mathrm{AD}$ are present at least 2-5 years prior to diagnosis and that this can be used to construct a battery that would support clinicians into identifying persons at risk of future decline. Table 1 indicates a set of measures with high predictive accuracy as well as additional more sensitive measures (in italics) or measures of brain reserve. This is the battery proposed by the Consortium for the early identification of AD-Quebec (CIMA-Q; http://www.cima-q.ca), of which three of the authors $(\mathrm{SB}, \mathrm{CH}$, and $\mathrm{SD})$ are leaders. The goal of CIMA-Q is to identify sensitive, valid, and clinically relevant functional and diagnostic markers, discover novel therapeutic targets, and refine

Table 1

Proposed CIMA-Q battery of tests to be used for early Alzheimer's disease detection based on meta-analysis with additional tasks in italics

\begin{tabular}{|c|c|c|c|}
\hline \multicolumn{4}{|c|}{ Cognitive functions } \\
\hline Memory & $\begin{array}{l}\text { Executive functions/Working } \\
\text { memory }\end{array}$ & Language & Perception \\
\hline $\begin{array}{l}\text { Rey Auditory Verbal Learning Test } \\
\text { (episodic memory) }\end{array}$ & Trail A and B (switching) & $\begin{array}{l}\text { Animal fluency (semantic } \\
\text { search) }\end{array}$ & $\begin{array}{l}\text { Object decision (BORB; } \\
\text { perceptual semantic) }\end{array}$ \\
\hline $\begin{array}{l}\text { Face-Name pairs task (associative } \\
\text { memory) }\end{array}$ & $\begin{array}{l}\text { Digit Symbol (processing } \\
\text { speed and working } \\
\text { memory) }\end{array}$ & $\begin{array}{l}\text { Boston naming (lexical and } \\
\text { semantic knowledge) }\end{array}$ & $\begin{array}{l}\text { Line Orientation (BORB; } \\
\text { visual discrimination) }\end{array}$ \\
\hline Free/cued recall (episodic encoding) & $\begin{array}{l}\text { Alpha span - short version } \\
\text { (working memory) }\end{array}$ & & \\
\hline Envelope test (prospective memory) & Hayling (inhibition) & & \\
\hline \multicolumn{4}{|c|}{ Questionnaires } \\
\hline Neuropsychiatry & Cognitive complaints & Reserve factors & Functional activities \\
\hline $\begin{array}{l}\text { Geriatric Depression Scale } \\
\text { (depression) } \\
\text { Geriatric Anxiety Inventory (anxiety) } \\
\text { Apathy Inventory (apathy) } \\
\text { Epworth Sleepiness Scale; Insomnia } \\
\text { Severity Index; Sleep duration } \\
\text { (sleep quality) }\end{array}$ & $\begin{array}{l}\text { Cognitive Change Index } \\
\text { Short version of the } Q A M\end{array}$ & $\begin{array}{l}\text { Victoria Longitudinal Study } \\
\text { Questionnaire } \\
\text { Questionnaire of variables } \\
\text { related to cognitive reserve }\end{array}$ & $A D C S-A D L$ \\
\hline \multicolumn{4}{|c|}{ Neuroimaging } \\
\hline Anatomical imaging & Pathological imaging & Vascular imaging & $\begin{array}{l}\text { Connectivity/Functional } \\
\text { imaging }\end{array}$ \\
\hline 3D T1w & $\mathrm{PD} / \mathrm{T} 2 \mathrm{w}$ & FLAIR; T2* & $\begin{array}{l}\text { 30-direction DT; resting state } \\
\text { BOLD } \\
\text { Task-related activation }\end{array}$ \\
\hline
\end{tabular}

Further information on neuroimaging parameters can be found at http://www.cdip-pcid.ca. BORB, Birmingham Object Recognition Battery; QAM, Questionnaire d'auto-évaluation de la mémoire, Memory Self-Evaluation Questionnaire; ADCS-ADL, Alzheimer's Disease Co-operative Study - Activities of Daily Living Inventory. 
preventive strategies. It involves a set of integrated research platforms including a longitudinal cohort registry of healthy older adults, MCI, and SCI who will receive multimodal assessment as identified in Table 1. Our literature review indicates that finding early markers of $\mathrm{AD}$ will require designing complex studies relying on a multidimensional approach, including larger sample sizes, combining multiple markers, and identifying populations at risk to enrich the sample. This will only be possible through large and collaborative research initiatives.

\section{ACKNOWLEDGMENTS}

This study was supported by Pfizer-FRQS funds to SB, CH, DLC, and SD, a FRSQ fund to SD, and CIHR funds to SB and DLC. SD and DLC are shareholders and officers of True Positive Medical Devices, Inc. DLC has received consulting income from NeuroRx Inc and Teva Inc. We thank Christine Saint-Pierre for support in the literature review and Gabrielle Ciquier for English edition.

Authors' disclosures available online (http://www.jalz.com/disclosures/view.php?id=2511).

\section{REFERENCES}

[1] Sperling RA, Aisen PS, Beckett LA, Bennett DA, Craft S, Fagan AM, Iwatsubo T, Jack CR Jr, Kaye J, Montine TJ, Park DC, Reiman EM, Rowe CC, Siemers E, Stern Y, Yaffe K, Carrillo MC, Thies B, Morrison-Bogorad M, Wagster MV, Phelps CH (2011) Toward defining the preclinical stages of Alzheimer's disease: Recommendations from the National Institute on Aging-Alzheimer's Association workgroups on diagnostic guidelines for Alzheimer's disease. Alzheimers Dement 7, 280-292.

[2] Bruscoli M, Lovestone S (2004) Is MCI really just early dementia? A systematic review of conversion studies. Int Psychogeriatr 16, 129-140.

[3] Moher D, Liberati A, Tetzlaff J, Altman DG, Group P (2009) Preferred reporting items for systematic reviews and metaanalyses: The PRISMA statement. PLoS Med 6, e1000097.

[4] Petersen RC, Smith GE, Waring SC, Ivnik RJ, Tangalos EG, Kokmen E (1999) Mild cognitive impairment: Clinical characterization and outcome. Arch Neurol 56, 303-308.

[5] Loewenstein DA, Acevedo A, Luis C, Crum T, Barker WW, Duara R (2004) Semantic interference deficits and the detection of mild Alzheimer's disease and mild cognitive impairment without dementia. J Int Neuropsychol Soc 10, 91-100.

[6] Ivanoiu A, Adam S, Van der Linden M, Salmon E, Juillerat AC, Mulligan R, Seron X (2005) Memory evaluation with a new cued recall test in patients with mild cognitive impairment and Alzheimer's disease. J Neurol 252, 47-55.

[7] Adam S, Van der Linden M, Ivanoiu A, Juillerat AC, Bechet S, Salmon E (2007) Optimization of encoding specificity for the diagnosis of early AD: The RI-48 task. J Clin Exp Neuropsychol 29, 477-487.
[8] Hudon C, Villeneuve S, Belleville S (2011) The effect of semantic orientation at encoding on free-recall performance in amnestic mild cognitive impairment and probable Alzheimer's disease. J Clin Exp Neuropsychol 33, 631-638.

[9] Villeneuve S, Belleville S (2012) The nature of memory failure in mild cognitive impairment: Examining association with neurobiological markers and effect of progression. Neurobiol Aging 33, 1967-1978.

[10] Nordahl CW, Ranganath C, Yonelinas AP, DeCarli C, Reed BR, Jagust WJ (2005) Different mechanisms of episodic memory failure in mild cognitive impairment. Neuropsychologia 43, 1688-1697.

[11] Hudon C, Belleville S, Gauthier S (2009) The assessment of recognition memory using the Remember/Know procedure in amnestic mild cognitive impairment and probable Alzheimer's disease. Brain Cogn 70, 171-179.

[12] Belleville S, Menard MC, Lepage E (2011) Impact of novelty and type of material on recognition in healthy older adults and persons with mild cognitive impairment. Neuropsychologia 49, 2856-2865.

[13] Gagnon LG, Belleville S (2011) Working memory in mild cognitive impairment and Alzheimer's disease: Contribution of forgetting and predictive value of complex span tasks. $\mathrm{Neu}$ ropsychology 25, 226-236.

[14] Belleville S, Chertkow H, Gauthier S (2007) Working memory and control of attention in persons with Alzheimer's disease and mild cognitive impairment. Neuropsychology 21, 458469.

[15] Alescio-Lautier B, Michel BF, Herrera C, Elahmadi A, Chambon C, Touzet C, Paban V (2007) Visual and visuospatial short-term memory in mild cognitive impairment and Alzheimer disease: Role of attention. Neuropsychologia $\mathbf{4 5}$, 1948-1960.

[16] Belleville S, Rouleau N, Van der Linden M (2006) Use of the Hayling task to measure inhibition of prepotent responses in normal aging and Alzheimer's disease. Brain Cogn 62, 113-119.

[17] Belanger S, Belleville S (2009) Semantic inhibition impairment in mild cognitive impairment: A distinctive feature of upcoming cognitive decline? Neuropsychology 23, 592-606.

[18] Bélanger S, Belleville S, Gauthier S (2010) Inhibition impairments in Alzheimer's disease, mild cognitive impairment and healthy aging: Effect of congruency proportion in a Stroop task. Neuropsychologia 48, 581-590.

[19] Rainville C, Lepage E, Gauthier S, Kergoat MJ, Belleville S (2012) Executive function deficits in persons with mild cognitive impairment: A study with a Tower of London task. $J$ Clin Exp Neuropsychol 34, 306-324.

[20] Wylie SA, Ridderinkhof KR, Eckerle MK, Manning CA (2007) Inefficient response inhibition in individuals with mild cognitive impairment. Neuropsychologia 45, 1408-1419.

[21] Dannhauser TM, Walker Z, Stevens T, Lee L, Seal M, Shergill SS (2005) The functional anatomy of divided attention in amnestic mild cognitive impairment. Brain 128, 1418-1427.

[22] Belleville S, Bherer L, Lepage E, Chertkow H, Gauthier S (2008) Task switching capacities in persons with Alzheimer's disease and mild cognitive impairment. Neuropsychologia 46, 2225-2233.

[23] Devanand DP, Liu X, Tabert MH, Pradhaban G, Cuasay K, Bell K, de Leon MJ, Doty RL, Stern Y, Pelton GH (2008) Combining early markers strongly predicts conversion from mild cognitive impairment to Alzheimer's disease. Biol Psychiatry 64, 871-879. 
[24] Lehrner J, Gufler R, Guttmann G, Maly J, Gleiss A, Auff E, Dal-Bianco P (2005) Annual conversion to Alzheimer disease among patients with memory complaints attending an outpatient memory clinic: The influence of amnestic mild cognitive impairment and the predictive value of neuropsychological testing. Wiener Klinische Wochenschrift 117, 629-635.

[25] Peters F, Villeneuve S, Belleville S (2014) Predicting progression to dementia in elderly subjects with mild cognitive impairment using both cognitive and neuroimaging predictors. J Alzheimers Dis 38, 307-318.

[26] Sarazin M, Berr C, De Rotrou J, Fabrigoule C, Pasquier F, Legrain S, Michel B, Puel M, Volteau M, Touchon J, Verny M, Dubois B (2007) Amnestic syndrome of the medial temporal type identifies prodromal AD: A longitudinal study.[Erratum appears in Neurology 70(21) (2008); 2016]. Neurology 69 1859-1867.

[27] Hanninen T, Hallikainen M, Koivisto K, Helkala EL, Reinikainen KJ, Soininen H, Mykkanen L, Laakso M, Pyorala K, Riekkinen PJ Sr (1995) A follow-up study of age-associated memory impairment: Neuropsychological predictors of dementia. J Am Geriatr Soc 43, 1007-1015.

[28] Rabin LA, Pare N, Saykin AJ, Brown MJ, Wishart HA, Flashman LA, Santulli RB (2009) Differential memory test sensitivity for diagnosing amnestic mild cognitive impairment and predicting conversion to Alzheimer's disease. Neuropsychol Dev Cogn B Aging Neuropsychol Cogn 16, 357-376.

[29] Eckerstrom C, Olsson E, Bjerke M, Malmgren H, Edman A, Wallin A, Nordlund A (2013) A combination of neuropsychological, neuroimaging, and cerebrospinal fluid markers predicts conversion from mild cognitive impairment to dementia. J Alzheimers Dis 36, 421-431.

[30] Tierney MC, Szalai JP, Snow WG, Fisher RH, Nores A, Nadon G, Dunn E, St George-Hyslop PH (1996) Prediction of probable Alzheimer's disease in memory-impaired patients: A prospective longitudinal study. Neurology 46, 661-665.

[31] Galton CJ, Erzinclioglu S, Sahakian BJ, Antoun N, Hodges JR (2005) A comparison of the Addenbrooke's Cognitive Examination (ACE), conventional neuropsychological assessment, and simple MRI-based medial temporal lobe evaluation in the early diagnosis of Alzheimer's disease. Cogn Behav Neurol 18, 144-150.

[32] Guarch J, Marcos T, Salamero M, Gasto C, Blesa R (2008) Mild cognitive impairment: A risk indicator of later dementia, or a preclinical phase of the disease? Int J Geriatr Psychiatry 23, 257-265.

[33] Didic M, Felician O, Barbeau EJ, Mancini J, Latger-Florence C, Tramoni E, Ceccaldi M (2013) Impaired visual recognition memory predicts Alzheimer's disease in amnestic mild cognitive impairment. Dement Geriatr Cogn Disord 35, 291-299.

[34] Griffith HR, Netson KL, Harrell LE, Zamrini EY, Brockington JC, Marson DC (2006) Amnestic mild cognitive impairment: Diagnostic outcomes and clinical prediction over a two-year time period. J Int Neuropsychol Soc 12, 166-175.

[35] Espinosa A, Alegret M, Valero S, Vinyes-Junque G, Hernandez I, Mauleon A, Rosende-Roca M, Ruiz A, Lopez O, Tarraga L, Boada M (2013) A longitudinal follow-up of 550 mild cognitive impairment patients: Evidence for large conversion to dementia rates and detection of major risk factors involved. J Alzheimers Dis 34, 769-780.

[36] Ewers M, Walsh C, Trojanowski JQ, Shaw LM, Petersen RC, Jack CR Jr, Feldman HH, Bokde AL, Alexander GE, Scheltens P, Vellas B, Dubois B, Weiner M, Hampel H, North American Alzheimer's Disease Neuroimaging I (2012) Prediction of conversion from mild cognitive impairment to
Alzheimer's disease dementia based upon biomarkers and neuropsychological test performance. Neurobiol Aging 33, 1203-1214.

[37] Albert MS, Moss MB, Tanzi R, Jones K (2001) Preclinical prediction of AD using neuropsychological tests. J Int Neuropsychol Soc 7, 631-639.

[38] Blackwell AD, Sahakian BJ, Vesey R, Semple JM, Robbins TW, Hodges JR (2004) Detecting dementia: Novel neuropsychological markers of preclinical Alzheimer's disease. Dement Geriatr Cogn Disord 17, 42-48.

[39] Ye BS, Seo SW, Lee Y, Kim SY, Choi SH, Lee YM, Kim do H, Han HJ, Na DL, Kim EJ (2012) Neuropsychological performance and conversion to Alzheimer's disease in early- compared to late-onset amnestic mild cognitive impairment: CREDOS study. Dement Geriatr Cogn Disord 34, 156-166.

[40] Gallagher D, Mhaolain AN, Coen R, Walsh C, Kilroy D, Belinski K, Bruce I, Coakley D, Walsh JB, Cunningham C, Lawlor BA (2010) Detecting prodromal Alzheimer's disease in mild cognitive impairment: Utility of the CAMCOG and other neuropsychological predictors. Int J Geriatr Psychiatry 25, 1280-1287.

[41] Chopard G, Vanholsbeeck G, Tio G, Pitard A, Binetruy M, Rumbach L, Galmiche J (2009) Rapid screening of cognitive change in patients with questionable dementia using the memory impairment screen and the Isaacs set test. J Am Geriatr Soc 57, 703-708.

[42] Belleville S, Gauthier S, Lepage E, Kergoat MJ, Gilbert B (2014) Predicting decline in mild cognitive impairment: A prospective cognitive study. Neuropsychology 28, 643-652.

[43] Artero S, Tierney MC, Touchon J, Ritchie K (2003) Prediction of transition from cognitive impairment to senile dementia: A prospective, longitudinal study. Acta Psychiatr Scand 107, 390-393.

[44] Derby CA, Burns LC, Wang C, Katz MJ, Zimmerman ME, L'Italien G, Guo Z, Berman RM, Lipton RB (2013) Screening for predementia AD: Time-dependent operating characteristics of episodic memory tests. Neurology 80, 1307-1314.

[45] Jessen F, Wiese B, Bickel H, Eifflander-Gorfer S, Fuchs A, Kaduszkiewicz H, Kohler M, Luck T, Mosch E, Pentzek M, Riedel-Heller SG, Wagner M, Weyerer S, Maier W, van den Bussche H, AgeCoDe Study G (2011) Prediction of dementia in primary care patients. PLoS One 6, e16852.

[46] Jungwirth S, Zehetmayer S, Bauer P, Weissgram S, Tragl KH, Fischer P (2009) Prediction of Alzheimer dementia with short neuropsychological instruments. J Neural Transm 116, 15131521.

[47] Hohman TJ, Beason-Held LL, Lamar M, Resnick SM (2011) Subjective cognitive complaints and longitudinal changes in memory and brain function. Neuropsychology 25, 125-130.

[48] Jessen F, Wolfsgruber S, Wiese B, Bickel H, Mosch E, Kaduszkiewicz H, Pentzek M, Riedel-Heller SG, Luck T, Fuchs A, Weyerer S, Werle J, van den Bussche H, Scherer M, Maier W, Wagner M, German Study on Aging C, Dementia in Primary Care P (2014) AD dementia risk in late MCI, in early MCI, and in subjective memory impairment. Alzheimers Dement 10, 76-83.

[49] Langlois AS, Belleville S (2014) Subjective cognitive complaint in healthy older adults: Identification of major domains and relation to objective performance. Neuropsychol Dev Cogn B Aging Neuropsychol Cogn 21, 257-282.

[50] Clément F, Belleville S, Gauthier S (2008) Cognitive complaint in mild cognitive impairment and Alzheimer's disease. J Int Neuropsychol Soc 14, 222-232. 
[51] Houde M, Bergman H, Whitehead V, Chertkow H (2008) A predictive depression pattern in mild cognitive impairment. Int J Geriatr Psychiatry 23, 1028-1033.

[52] Teng E, Lu PH, Cummings JL (2007) Neuropsychiatric symptoms are associated with progression from mild cognitive impairment to Alzheimer's disease. Dement Geriatr Cogn Disord 24, 253-259.

[53] Palmer K, Di Iulio F, Varsi AE, Gianni W, Sancesario G, Caltagirone C, Spalletta G (2010) Neuropsychiatric predictors of progression from amnestic - Mild cognitive impairment to alzheimer's disease: The role of depression and apathy. $J$ Alzheimers Dis 20, 175-183.

[54] Lobo A, Lopez-Anton R, de-la-Camara C, Quintanilla MA, Campayo A, Saz P, Workgroup Z (2008) Non-cognitive psychopathological symptoms associated with incident mild cognitive impairment and dementia, Alzheimer's type. Neurotox Res 14, 263-272.

[55] Braak H, Braak E (1991) Neuropathological stageing of Alzheimer-related changes. Acta Neuropathol 82, 239-259.

[56] Jack CR Jr, Dickson DW, Parisi JE, Xu YC, Cha RH, O'Brien PC, Edland SD, Smith GE, Boeve BF, Tangalos EG, Kokmen E, Petersen RC (2002) Antemortem MRI findings correlate with hippocampal neuropathology in typical aging and dementia. Neurology 58, 750-757.

[57] Jack CR Jr, Petersen RC, Xu Y, O’Brien PC, Smith GE, Ivnik RJ, Boeve BF, Tangalos EG, Kokmen E (2000) Rates of hippocampal atrophy correlate with change in clinical status in aging and AD. Neurology 55, 484-489.

[58] Apostolova LG, Dutton RA, Dinov ID, Hayashi KM, Toga AW, Cummings JL, Thompson PM (2006) Conversion of mild cognitive impairment to Alzheimer disease predicted by hippocampal atrophy maps. Arch Neurol 63, 693-699.

[59] Pennanen C, Kivipelto M, Tuomainen S, Hartikainen P, Hanninen T, Laakso MP, Hallikainen M, Vanhanen M, Nissinen A, Helkala EL, Vainio P, Vanninen R, Partanen K, Soininen H (2004) Hippocampus and entorhinal cortex in mild cognitive impairment and early AD. Neurobiol Aging 25, 303-310.

[60] Fleisher AS, Sun S, Taylor C, Ward CP, Gamst AC, Petersen RC, Jack CR, Aisen PS, Thal LJ (2008) Volumetric MRI vs clinical predictors of Alzheimer disease in mild cognitive impairment. Neurology 70, 191-199.

[61] Stewart R, Dufouil C, Godin O, Ritchie K, Maillard P, Delcroix N, Crivello F, Mazoyer B, Tzourio C (2008) Neuroimaging correlates of subjective memory deficits in a community population. Neurology 70, 1601-1607.

[62] Stewart R, Godin O, Crivello F, Maillard P, Mazoyer B, Tzourio C, Dufouil C (2011) Longitudinal neuroimaging correlates of subjective memory impairment: 4-year prospective community study. Br J Psychiatry 198, 199-205.

[63] DeCarli C, Frisoni GB, Clark CM, Harvey D, Grundman M, Petersen RC, Thal LJ, Jin S, Jack CR Jr, Scheltens P, Alzheimer's Disease Cooperative Study G (2007) Qualitative estimates of medial temporal atrophy as a predictor of progression from mild cognitive impairment to dementia. Arch Neurol 64, 108-115.

[64] Risacher SL, Saykin AJ, West JD, Shen L, Firpi HA, McDonald BC (2009) Baseline MRI predictors of conversion from
MCI to probable AD in the ADNI cohort. Curr Alzheimer Res 6, 347-361.

[65] Risacher SL, Shen L, West JD, Kim S, McDonald BC, Beckett LA, Harvey DJ, Jack CR Jr, Weiner MW, Saykin AJ (2010) Longitudinal MRI atrophy biomarkers: Relationship to conversion in the ADNI cohort. Neurobiol Aging 31, 1401-1418.

[66] Leow AD, Yanovsky I, Parikshak N, Hua X, Lee S, Toga AW, Jack CR Jr, Bernstein MA, Britson PJ, Gunter JL, Ward CP, Borowski B, Shaw LM, Trojanowski JQ, Fleisher AS, Harvey D, Kornak J, Schuff N, Alexander GE, Weiner MW, Thompson PM (2009) Alzheimer's disease neuroimaging initiative: A one-year follow up study using tensor-based morphometry correlating degenerative rates, biomarkers and cognition. Neuroimage 45, 645-655.

[67] Jack CR Jr, Shiung MM, Gunter JL, O'Brien PC, Weigand SD, Knopman DS, Boeve BF, Ivnik RJ, Smith GE, Cha RH, Tangalos EG, Petersen RC (2004) Comparison of different MRI brain atrophy rate measures with clinical disease progression in AD. Neurology 62, 591-600.

[68] Querbes O, Aubry F, Pariente J, Lotterie JA, Demonet JF, Duret V, Puel M, Berry I, Fort JC, Celsis P (2009) Early diagnosis of Alzheimer's disease using cortical thickness: Impact of cognitive reserve. Brain 132, 2036-2047.

[69] Duchesne S, Bocti C, De Sousa K, Frisoni GB, Chertkow H, Collins DL (2010) Amnestic MCI future clinical status prediction using baseline MRI features. Neurobiol Aging 31, 1606-1617.

[70] Fan Y, Batmanghelich N, Clark CM, Davatzikos C (2008) Spatial patterns of brain atrophy in MCI patients, identified via high-dimensional pattern classification, predict subsequent cognitive decline. Neuroimage 39, 1731-1743.

[71] Peter J, Scheef L, Abdulkadir A, Boecker H, Heneka M, Wagner M, Koppara A, Kloppel S, Jessen F, Alzheimer's Disease Neuroimaging I (2014) Gray matter atrophy pattern in elderly with subjective memory impairment. Alzheimers Dement 10, 99-108.

[72] Resnick SM, Goldszal AF, Davatzikos C, Golski S, Kraut MA, Metter EJ, Bryan RN, Zonderman AB (2000) One-year age changes in MRI brain volumes in older adults. Cereb Cortex 10, 464-472.

[73] Dickerson BC, Salat DH, Greve DN, Chua EF, RandGiovannetti E, Rentz DM, Bertram L, Mullin K, Tanzi RE, Blacker D, Albert MS, Sperling RA (2005) Increased hippocampal activation in mild cognitive impairment compared to normal aging and AD. Neurology $\mathbf{6 5}, 404-411$.

[74] Sperling R (2007) Functional MRI studies of associative encoding in normal aging, mild cognitive impairment, and Alzheimer's disease. Ann N Y Acad Sci 1097, 146-155.

[75] Clement F, Belleville S (2010) Compensation and disease severity on the memory-related activations in mild cognitive impairment. Biol Psychiatry 68, 894-902.

[76] Clement F, Belleville S (2012) Effect of disease severity on neural compensation of item and associative recognition in mild cognitive impairment. J Alzheimers Dis 29, 109-123.

[77] Galluzzi S, Frisoni GB (2008) Imaging, subjective complaints, and MCI: 30 years before. J Nutr Health Aging 12, 80S-83S. 